\title{
Determinantes da ecoeficiência: uma análise através da regressão
}

\section{Tobit}

O objetivo desta pesquisa foi determinar através de uma Regressão Tobit as variáveis que tiveram maior impacto no Índice de Ecoeficiência dos países. Das variáveis explicativas utilizadas no modelo de regressão, o Rebanho Total/Área Rural foi a única que não se mostrou significante. Formação Bruta de Capital Fixo, Consumo de Combustíveis Fósseis e Rendas de Carvão possuem um efeito negativo sobre o escore de ecoeficiência, enquanto as variáveis Taxa de Alfabetização de Adultos e Qualidade do Governo geram um efeito positivo. A principal implicação dos resultados obtidos é de que são necessárias regulamentações mais rigorosas acerca do tema ambiental, buscando assim ampliar o conhecimento sobre o assunto para propor melhores alternativas de se alcançar a sustentabilidade tão necessária para as futuras gerações.

Palavras-chave: Ecoeficiência; Desenvolvimento; Preservação; Regressão Tobit.

\section{Determinants of ecoefficiency: an analysis through the Tobit regression}

\begin{abstract}
The objective of this research was to determine, through a Tobit regression, the variables that had the greatest impact on the countries' Eco-efficiency Index. Of the explanatory variables used in the regression model, the Total Herd / Rural Area was the only one that was not significant. Gross Formation of Fixed Capital, Consumption of Fossil Fuels and Coal Rents have a negative effect on the eco-efficiency score, while the variables Adult Literacy Rate and Government Quality have a positive effect. The main implication of the results obtained is that stricter regulations are needed on the environmental theme, thus seeking to broaden the knowledge on the subject to propose better alternatives to achieve the much needed sustainability for future generations.
\end{abstract}

Keywords: Eco-efficiency; Development; Preservation; Tobit Regression.

Topic: Valoração e Economia Ambiental

Reviewed anonymously in the process of blind peer.
Received: 14/12/2017

Approved: 24/01/2018
Harine Matos Maciel (iD

Universidade Federal do Ceará, Brasil

http://lattes.cnpq.br/0030988397237524

http://orcid.org/0000-0003-3267-6198

harinematos@yahoo.com.br

Ahmad Saeed Khan

Universidade Federal do Ceará, Brasil

http://lattes.cnpq.br/3198350508846033

http://orcid.org/0000-0001-5606-2719

harinematos@yahoo.com.br

\section{Leonardo Andrade Rocha (iD}

Universidade Federal Rural do Semi-Árido, Brasil

http://lattes.cnpq.br/1760530300831377

http://orcid.org/0000-0003-2777-0702

harinematos@yahoo.com.br
Referencing this:

MACIEL, H. M.; KHAN, A. S.; ROCHA, L. A.. Determinantes da ecoeficiência: uma análise através da regressão Tobit. Revista Ibero Americana de Ciências Ambientais, v.9, n.2, p.365-381, 2018. DOI: http://doi.org/10.6008/CBPC2179-6858.2018.002.0029 


\section{INTRODUÇÃO}

A revolução industrial trouxe mudanças significativas para a sociedade. Antes os meios de produção eram artesanais e as quantidades produzidas eram apenas o suficiente para as necessidades básicas, porém a Revolução Industrial modificou a interação do homem com o meio ambiente. O consumo de combustíveis, necessários para o funcionamento de máquinas e carros, principalmente os fósseis (carvão, óleo e gasolina) aumentou exponencialmente trazendo malefícios aos planetas.

O ser humano vem provocado ao longo do tempo inúmeros impactos aos ambientes naturais. $\mathrm{O}$ avanço do crescimento econômico agravou os problemas ambientais como a contaminação da água, destruição da fauna e flora, uso intensivo de agrotóxicos, mau uso do solo, falta de técnicas adequadas de manejo dos animais, entre outros. Segundo Gonçalves (2007) o nível de intervenção do homem na natureza, é tão grande que se torna quase impossível encontrar natureza ou ecossistemas puros.

Os homens usufruem de alguns bens que a natureza concede gratuitamente, como o ar, a água e a luz do sol. Não são esses os bens aos quais, na acepção corrente, chamam de riquezas. Os recursos naturais eram utilizados como mercadorias que poderiam ter reposição a qualquer momento, porém o uso desmedido mostrou que estes recursos são limitados e podem esgotar, além de influenciar diretamente a qualidade de vida da população através, por exemplo, do aumento de temperatura e da poluição excessiva (SAY, 1986).

As mudanças necessárias para se adotar ações preventivas aos recursos ambientais vieram com mais vigor com o conceito de desenvolvimento sustentável, conceito este que mostra a sociedade que os recursos naturais não suportariam a exploração intensa muito mais tempo, além dos efeitos danosos que já fazem parte do dia a dia da população como o aumento dos gases do efeito estufa, chuva ácida, erosão dos solos, entre outros. O Desenvolvimento Sustentável reconhece a importância dos recursos ambientais para as atividades produtivas. Todavia este conceito ainda é bastante discutido entre os estudiosos e não se chegou a um denominador comum e em razão disso há inúmeros trabalhos e pesquisas na área em busca do conceito mais completo.

No início do século XXI o desenvolvimento sustentável passou a ser de fato um tema incontestável para as políticas públicas dos países. Os países se comprometeram a focar no bem-estar econômico, qualidade ambiental e estabilidade social, porém como colocar esses planos em prática eram a grande questão. $O$ estudo da eficiência econômica e ambiental (ecoeficiência) surgiu nos anos noventa como uma nova ferramenta na busca por melhores soluções para continuar aumentando a produção e, simultaneamente, reduzindo os impactos causados aos ambientes naturais.

Nos últimos anos este tema tem recebido atenção especial de pesquisadores, já que estes enfrentam o desafio de fornecer aos formuladores de políticas ambientais informações e possíveis soluções para o conflito de interesses entre produtores, consumidores e ambientalistas. A ecoeficiência veio para contribuir na luta contra a exploração dos ambientes naturais, pois era necessário e urgente que ocorresse uma modificação na relação entre o ser humano e a natureza, que é exploratória, criando barreiras para o futuro 
ao utilizar de forma desmedida os recursos, produzindo a escassez, poluindo o ambiente, desmatando, extinguindo espécies e aquecendo o planeta.

Este estudo mundial é relevante para mostrar como os países tem se comportado e como as políticas econômicas e ambientais podem auxiliar na melhoria desses resultados. Neste contexto, o objetivo da pesquisa foi estimar uma regressão Tobit para analisar quais variáveis possuem o maior poder de explicação do Índice de Ecoeficiência, para uma amostra heterogênea de países, 51 no total, distribuídos nos cinco continentes, no período entre 1991 a 2012.

\section{REVISÃO TEÓRICA}

\section{Política ambiental e ecoeficiência}

A interligação entre o desenvolvimento socioeconômico e as transformações do meio ambiente, durante décadas ignorada, entrou no discurso oficial da maioria dos governos do mundo (BRUSEKE, 1996). A política ambiental pode ser definida como o conjunto de normas e instrumentos que visam reduzir os impactos negativos da ação do homem sobre o meio ambiente (LUSTOSA et al., 2002). O debate sobre política ambiental é muito incipiente no Brasil, diferente do que ocorre em outros países, já mais avançados quando se trata deste assunto.

O modelo de gestão ambiental brasileiro consiste na Política Nacional de Meio Ambiente (Lei n.6938 de 31/08/1991). De acordo com Lustosa et al. (2002) a política ambiental brasileira elaborada a partir da Conferência de Estocolmo fundamentou-se basicamente no controle da poluição e na criação de unidades de conservação da natureza. Não era o ideal, já que o uso dos recursos naturais abrange diversas situações, mas já era o início de uma preocupação em proteger os ambientes naturais.

A política ambiental brasileira iniciou-se no primeiro governo de Getúlio Vargas com o objetivo de ordenar o uso dos recursos naturais. No ano de 1934 foi criado o Código Florestal, das Águas, Minas, Caça e Pesca e a primeira Conferência Brasileira de Proteção à Natureza, além da criação, em 1937, do Parque Nacional de Itatiaia e da legislação de proteção ao patrimônio histórico e artístico nacional. De acordo com Sirvinskas (2009), o encontro 'Eco-92' marcou a discussão a respeito do desenvolvimento sustentável, realizada no Brasil, com a participação de representantes de quase todos os países para debater a necessidade de internalização dos problemas ambientais nos processos decisórios, tanto no âmbito político quanto no econômico.

Ainda na Eco-92 foi elaborada a Agenda 21. De acordo com o Ministério do Meio Ambiente (2013) a Agenda 21 foi um instrumento de planejamento para a construção de sociedades sustentáveis, em diferentes bases geográficas, que concilia métodos de proteção ambiental, justiça social e eficiência econômica, ligados ao combate à desertificação e à resistência aos efeitos das secas nas zonas áridas, semiáridas e subúmidas secas do planeta. Não só no Brasil, mas a grande maioria dos países estavam seguindo a lógica dos mercados capitalistas, a busca pela expansão da industrialização e o consequente crescimento da economia, deixando 
assim a implementação de importantes e necessárias políticas. Nos anos 90, diversos países elaboraram seus planos nacionais estratégicos de desenvolvimento sustentável.

A maior parte dos países utilizam incentivos econômicos como parte integrante das políticas ambientais, pois incentivam as empresas a adotarem práticas mais eficientes, buscando aproveitar o máximo possível os recursos naturais, e em conjunto desenvolver tecnologias que necessitem cada vez menos destes recursos. Adotar tecnologias ambientalmente aceitas não é fácil para as empresas, pois estas não são baratas e o custo benefício nem sempre ocorrem como as empresas almejam, já que o objetivo principal é o constante crescimento e não a conservação dos ambientes naturais. Segundo Aidt (1998) existe motivação dos agentes econômicos para influenciar no processo de escolha dos instrumentos de políticas ambientais a ser implementados, pode haver uma colisão entre os interesses corporativos e os sociais.

O principal objetivo das políticas ambientais é a conscientização da população de que é essencial proteger os ambientes naturais, apesar disso muitas políticas não levam em consideração a cultura e o modo de viver de uma sociedade, sua relação com a natureza, vislumbrando a sociedade como um todo, sem suas particularidades. O poder público local deve atuar como orientador dessas políticas, examinando o comportamento de sua população e adequando as políticas que serão implementadas para que a população se sinta parte do ambiente em que vive, contribuindo de forma ativa na conservação desses ambientes, uma vez que sem a participação desta população, nenhuma política ambiental alcançará o sucesso.

É difícil comparar os benefícios sociais da proteção ambiental com o custo dessa proteção; difícil julgar a melhor forma de os governos intervirem; difícil ter certeza, em alguns casos, até mesmo dos fatos, tais como a taxa de perda de espécies ou de desmatamento, e muito menos de como interpretá-los (THE ECONOMIST, 1999). É necessário a aplicação de políticas ambientais globais, já que o sistema econômico vigente possui um objetivo definido que é o retorno financeiro, mas é preciso as restrições ao uso dos recursos naturais, alguns exemplos de países auxiliam nessa tomada de decisão global.

Segundo Kamieniecki et al. (2012), desde o primeiro Dia da Terra nos Estados Unidos, em abril de 1970, os governos federal, estadual e local adotaram dezenas de leis e regulamentos para controlar a poluição e proteger os recursos naturais. Foram criadas novas instituições, como a Agência de Proteção Ambiental dos Estados Unidos (EPA), e os governos assumiram uma ampla gama de novas responsabilidades. Muitas das leis ambientais norte americanas foram criadas entre os anos 60 e 70. Além da EPA criada em 1970, em 1969 a Lei Nacional de Política Ambiental e posteriormente leis contra poluição da água, solo e o acúmulo de resíduos sólidos.

A China, o maior poluidor dos gases do efeito estufa, enfrenta graves problemas referentes, principalmente, a infraestrutura das cidades, já que utilizam intensamente o carvão para diversas atividades empresariais e domésticas, poluindo agua, ar e gerando muito lixo. Há uma má gestão ambiental e por isso o governo tem investido bastante em educação ambiental não só nas escolas, mas também no ensino superior. Foi nos anos setenta que os chineses aprovaram a sua Lei de Proteção Ambiental, exigindo que cada novo projeto atendesse as regulamentações ambientais. Segundo o Centro de Estudos em Sustentabilidade da Fundação Getúlio Vargas no ano de 2008 a China criou o Ministério da Proteção 
Ambiental (MEP) com a meta de realizar sérios esforços para melhorar o meio ambiente, o MEP é o principal órgão de formulação e execução de políticas ambientais.

$\mathrm{Na}$ Índia ainda há muita exploração das florestas e o uso intensivo dos solos para atividades agrícolas, contribuindo assim para a degradação dos ambientes naturais. A industrialização e o aumento do setor de transportes também contribuem para a intensa poluição do ar, porém a proteção ambiental tem melhorado nos últimos anos devido as legislações ambientais e ao interesse da população em reverter essa situação. A governança ambiental passou a ter importância no país, assim houve evolução do estatuto jurídico para a conservação de parques nacionais, reservas florestais e animais selvagens. Na constituição do Uruguai, criada nos anos sessenta, havia apenas um artigo que tratava do meio ambiente. Nos anos noventa, devido ao intenso debate mundial, os uruguaios legislaram acerca da responsabilidade do governo e da sociedade em preservar os recursos naturais.

O Uruguai tem apresentado uma evolução significativa em sua legislação ambiental, destacando-se o Código de Águas de 1979; a criação do Ministério do Meio Ambiente; Lei de Avaliação de Impactos Ambientais de 1994, que subordina a execução das atividades à obtenção de uma licença prévia, que será conferida após a realização do estudo de impacto ambiental; Lei da Irrigação, por meio da qual se instituiu a gestão tríplice de recursos hídricos, envolvendo os Ministérios do Meio Ambiente, dos Transportes e Obras Públicas e de Agricultura; a aprovação em 1998, do Protocolo Ambiental do Mercosul; a Lei de 2000, que criou um sistema de áreas protegidas e outorgou ao Ministério do Meio Ambiente a polícia ambiental e criou unidades em cada zona do País, envolvendo, na sua implementação, cooperativas, cidadãos e o apoio técnico da universidade; Lei Geral de Preservação do Meio Ambiente em 2001; a criação do Probides - órgão tripartite para o estudo da biodiversidade, integrado pelo Ministério do Meio Ambiente e pela universidade, além da fundação, em 1995, do Grupo de Montevideo das Universidades do Mercosul, que possui uma área ambiental, com intercâmbio de docentes, convênios, pesquisas, etc. e uma área específica sobre águas (VIANA, 2004).

Noruega possui belas paisagens e parques bastante frequentados por sua população. O compromisso com a proteção dos ambientes naturais tanto pelo governo quanto pela população, fez da Noruega um país exemplo nessa área. Além de possui o maior Índice de Desenvolvimento Humano, possuem políticas ambientais que de fato funcionam como, por exemplo, na área de manejo eficiente da água, ar e solo e no uso de energias renováveis. Um dos projetos mais famosos foi o Estado Verde, criado no ano de 1988, com a meta de acompanhar e certificar as atividades relativas ao setor de energia, transporte, uso de tecnologias de informação e comunicações, estratégias de gestão de resíduos e produção agrícola.

A política de proteção climática é relativamente jovem na Alemanha. Suas origens vêm de uma discussão sobre a política ambiental mais ampla - sobretudo no âmbito internacional - que influiu politicamente no país através de publicações famosas como o estudo sobre 'Os limites do crescimento' do Clube de Roma de 1972. Na mesma Alemanha, a morte dos bosques nos anos 1980 tornou necessárias pela primeira vez várias medidas de política ambiental. Emissões industriais contendo dióxido de enxofre e gases do escapamento dos automóveis, com seu conteúdo de chumbo, causaram um deterioramento alarmante 
dos bosques e florestas. Foi Helmut Kohl (CDU, partido da União Democrata Cristã), o então chanceler, que estabeleceu um marco regulamentar ambiental que resultou em uma melhora notável do meio ambiente (EKLA, 2016).

Foi na Alemanha que surgiu o conceito de política industrial ecológica, no ano de 2006, com o objetivo de reformar a tributação ecológica alemã, endurecer as leis de energias renováveis e reciclagem. Os franceses também desenvolveram suas legislações ambientais, mas foi com a criação da Lei Grenolleenvironnement que ocorreu a união de forças entre governos, empresas e população na busca por harmonizar a ecologia, economia e o planejamento sustentável. Essa lei, criada em 2007, estabelecia metas para reduzir a emissão dos gases do efeito estufa, principalmente o $\mathrm{CO}_{2}$, e recuperar os ambientes naturais. De acordo com Yamaguchi et al. (2011) essa lei é nos dias atuais a mais efetiva na luta contra as mudanças climáticas, comparada até com o protocolo de Kyoto.

A política ambiental durante muitos anos não ocupou uma posição de destaque nas leis russas. A população, em geral, não se importava com o assunto aquecimento global, porque como o clima do país é muito frio, para eles os aumentos das temperaturas trariam mais vantagens como um ambiente com temperaturas mais amenas.

Para construir uma imagem de maior responsabilidade ambiental, o governo em 2001 lançou a 'Doutrina ecológica'. Em 2002 criou a lei de proteção ao meio ambiente, na qual foi enunciado o direito do indivíduo a um meio ambiente saudável, garantido pela harmonização de interesses econômicos e sociais do indivíduo, da sociedade e do Estado, o que deveria assegurar o desenvolvimento sustentável do país. Introduzindo o conceito de 'segurança ecológica', que inscreve a percepção russa das questões de sustentabilidade e meio ambiente dentro do âmbito da segurança e que teve consequências posteriores na política russa para o meio ambiente. A inserção da questão ambiental dentro das discussões de segurança tem feito com que o Estado russo privilegie a compreensão do meio ambiente principalmente em alguns poucos assuntos, como medidas de prevenção de desastre, modernização das indústrias, acordos bilaterais e introdução de novas tecnologias (SILVA et al., 2012).

Os canadenses têm bastante interesse nos assuntos referentes ao meio e ambiente e a sua preservação, e o governo dá respostas positivas através de leis e regulamentos que possuem efeitos positivos na indústria, tecnologia e inovação ambiental. Uma das principais leis canadenses foi criada no ano de 1991, a lei de Avaliação de Impacto Ambiental (Canadian Environmental Assessment Act - CEAA).

A CEAA foi estabelecida com o intuito de assegurar que os órgãos e agências competentes considerassem as questões ambientais nos processos decisórios. CEAA é administrada pela Canadian Environmental Assessment Agency, instituição federal responsável pela administração do processo de AIA federal no Canadá. Dentre seus objetivos, destacam-se o monitoramento dos estudos ambientais e a responsabilidade por assegurar a participação pública. No Canadá, os estudos ambientais são denominados Environmental Assessment - EA - e envolvem as etapas de construção, operação, alteração, descomissionamento e fechamento (PIAGENTINI et al., 2014). 
Apesar da Austrália possuir um grande patrimônio ambiental, o país utiliza intensamente fontes de energias não renováveis como carvão, petróleo e gás natural. Mesmo diante desta situação, os australianos têm bastante consciência ecológica e pressionam os governos a se preocupar com o tema. Nos anos setenta foram criadas leis ambientais, mas na prática o que se via era a dominância do aspecto econômico. Na década de noventa houve avanços na legislação como o Programa Nacional de Energia que estabelecia padrões de desempenho e certificação, e uma ampliação da proteção ambiental.

A Austrália é signatária de diversos acordos internacionais de natureza ambiental, como Protocolo Ambiental da Antártica, Tratado da Antártica, Convenção sobre Diversidade Biológica, Convenção sobre a Mudança do Clima, Convenção sobre o Comércio Internacional das Espécies da Fauna e Flora Selvagens em Perigo de Extinção (CITES), Convenção da Basiléia sobre Resíduos Perigosos, Lei do Mar, Convenção sobre a Conservação dos Recursos Vivos Marinhos Antárticos, Tratado para a Proibição Completa dos Testes Nucleares, Protocolo de Montreal sobre as Substâncias que Esgotam a Camada de Ozônio, Madeira Tropical, Florestas Tropicais, Convenção Internacional para a Regulamentação da Pesca da Baleia, entre outros (LUSTOSA, 2007).

No México ocorreu uma reforma constitucional com o objetivo de diminuir os impactos ambientais ao criar a Lei Geral de Equilíbrio Ecológico em 1988. Alguns anos depois foram criados o Instituto Nacional de Ecologia e a Procuradoria Federal de Proteção Ambiental. Alguns instrumentos econômicos da política ambiental mexicana são o imposto adicional sobre a gasolina na área metropolitana da Cidade do México, multas cobradas na pesca e silvicultura; cobrança de taxas para a descarga de águas residuais industriais, para empresas e municípios que excedam os limites estabelecidos pelas regras, a cobrança de taxas para a utilização ou exploração de bens públicos, entre outros (CALDERÓN, 2010).

A gestão de recursos naturais em Moçambique não constituía uma prioridade para os governantes. As principais leis eram acerca do uso das terras e florestas. O país necessita de investimentos em diversos setores e suas prioridades ambientais são nas áreas de saneamento, educação ambiental, cumprimento da legislação e capacitação institucional, redução da poluição do ar, águas, e solos e a prevenção e redução dos resíduos.

Segundo Nicurebede (2013) as políticas ambientais iniciaram com a Constituição da República de Moçambique de 1990, Lei do Ambiente (Lei no 20/97, de 01 de Outubro), Lei de Floresta, Lei de Minas, Lei de Águas, Política e Lei do Ambiente, Regulamento Sobre Pesticidas, Regulamento Sobre a Gestão de Lixos Bio-Médicos, Regulamento Sobre os Padrões de Qualidade Ambiental e de emissão de efluentes; Regulamento Sobre o Processo de Avaliação do Impacto Ambiental; Regulamento Sobre a Inspeção Ambiental; Regulamento Para a Prevenção da Poluição e proteção do Ambiente Marinho e Costeiro.

O Japão implementou medidas para empresas e sociedade para que estes pudessem viver regulados pelas leis ambientais, buscando novas tecnologias voltadas para o uso eficiente de recursos naturais. De acordo com o Ministério dos Negócios Estrangeiros do Japão (2012), em 1967 foi sancionada a Lei de Prevenção da Poluição Ambiental, no ano seguinte a Lei de Controle da Poluição do Ar e a Lei de Regulação de Ruídos, na década de setenta foi inaugurada a Agência Ambiental, hoje Ministério do Meio Ambiente e a 
Lei de Preservação da Natureza. Nos anos noventa foi criada a Lei Básica de Meio Ambiente. Já o ano de 2000 foi o ano em que a 'sociedade dos ciclos materiais' do Japão nasceu com uma estrutura fundamental para estimular e promover os '3R' (Reduzir, Reutilizar e Reciclar).

Um dos grandes desafios é fortalecer os mecanismos para garantir a adequada a integração, a coerência e a coordenação entre as políticas públicas e entre os diferentes níveis de governo e agentes econômicos envolvidos na consecução das metas de desenvolvimento sustentável. Nenhum país é sustentável a longo prazo, é necessário administrar e preservar os recursos naturais, já que estes não suportariam o ritmo de crescimento econômico dos últimos anos. Já se conhece o conceito e os objetivos do desenvolvimento sustentável, mas como se fazer para alcançá-lo é que continua em discussão há vários anos, já que não se chega a um denominador comum, a uma forma consistente de se alcançar o tão almejado desenvolvimento sustentável das nações.

O governo tem sim uma participação essencial nos aspectos econômicos, sociais, ambientais, culturais, entre outros, com o objetivo de tornar o ambiente melhor para se viver, aumentando o bem-estar da população. A política ambiental ideal seria aquela capaz de incorporar as diversas dimensões da sociedade, sociais, ambientais, políticas e econômicas, pois somente assim poderia ocorrer um verdadeiro desenvolvimento sustentável, preservando a qualidade de vida da população e os ambientes naturais.

O desenvolvimento sustentável é uma responsabilidade de todos os agentes da sociedade e para alcançá-lo são necessárias ações coletivas para proteger o meio ambiente, buscando opções de produção menos danosas aos recursos naturais, o conceito de ecoeficiência surgiu desta necessidade. $\mathrm{O}$ significado de ecoeficiência foi citado pela primeira vez por Schaltegger e Sturm na Suíça no ano de 1990, porém, a implementação de políticas e modelos de gestão que tratassem de controle da poluição e redução de resíduos, sem esquecer o lado econômico, datam de algumas décadas anteriores, a década de 70.

De acordo com Erkko et al. (2005) consiste na busca pelo desenvolvimento sustentável nos negócios, combinando eficiências econômicas e ambientais. Esta quer estes dois lados, econômico e ambiental, que parecem opostos, já que durante muitos anos pensou-se que o lado ambiental prejudicaria os retornos financeiros dos negócios, e a ecoeficiência mostra que é possível trabalhar em conjunto com esses dois lados. O conceito está em constante evolução, já que o ajustamento do desempenho econômico com o ambiental continua sendo aprimorado, porque inicialmente não se acreditavam que trariam de fato melhorias ambientais. O princípio é fabricar mais produtos com menos material, tornando os produtos mais competitivos e atendendo as exigências do mercado.

Para o Conselho Empresarial Mundial para o Desenvolvimento Sustentável (World Business Council for Sustainable Development - WBCSD - 1992) é a geração de bens e serviços a preços competitivos que satisfaçam as necessidades humanas e possibilitem melhor qualidade de vida, ao mesmo tempo em que reduzem progressivamente os impactos ambientais e o uso de recursos naturais ao longo do ciclo de vida destes bens e serviços até, pelo menos, o nível de sustentabilidade do planeta.

A década de 90 consolidou o conceito, buscando assim diminuir a distância entre o avanço econômico e a utilização dos recursos da natureza, mostrando que é importante para as empresas adotarem 
este conceito. Já que na década passada o que ocorria no âmbito ecológico eram o cumprimento das leis ambientais, mas sem se importar com o meio ambiente, e sim com os retornos financeiros. Com o avanço da tecnologia o processo produtivo passou a ser mais ágil e eficiente, necessitando assim de uma quantidade cada vez maior de recursos ambientais. Por um lado, as empresas aumentavam seus lucros e por outro lado os recursos passaram a se tornar escassos, fazendo com que as empresas vissem na ecoeficiência uma maneira de melhorar sua imagem, já que a sociedade estava cobrando cada dia mais a eficiência ambiental das empresas.

A ecoeficiência sozinha não é mais suficiente. Embora considere aspectos econômicos e ecológicos e, portanto, leva a processos de produção com menos recursos e menos impacto no meio ambiente, os aspectos sociais estão fora desta metodologia. Esta também pode ser utilizada para auxiliar governos na criação de políticas públicas com o objetivo de alcançar o desenvolvimento sustentável de um país, já que tem sido uma das ferramentas mais populares na luta contra a exploração desmedida dos ambientes naturais, mostrando que é uma importante ferramenta de gestão ambiental e sustentabilidade não só para as empresas, mas para políticas públicas também.

Para Lehni (2000) é utilizada como indicador para quantificar o progresso de um país para o desenvolvimento sustentável. Braungart et al. (2006) a concebem como uma estratégia de ação social, pela qual a finalidade é reduzir o uso de materiais na economia com vistas a minimizar impactos ambientais indesejáveis e produzir níveis relativamente mais altos de riquezas econômicas, que deverão ser distribuídas de maneira mais justa. A ecoeficiência é muito importante para as políticas públicas e diversos países já estão adotando para disseminar a ideia, buscando envolver todos os atores da sociedade e assim criar uma nova cultura do uso eficiente dos recursos naturais.

O consumo da população influencia diretamente a eficiência, pois quando a maior parte da população prefere sair de casa no seu próprio carro e não no transporte público, estão poluindo mais o ambiente, ou quando gastam mais água e energia que o necessário. O autor Chung (2006) resume muito bem esta ideia quando afirma que a "ecoeficiência deve ser o foco dos padrões de consumo". Para que num futuro não muito distante a população possa ter mais consciência ecológica e se torne menos consumista, contribuindo assim para a preservação dos recursos para as gerações futuras.

Cada país possui sua especificidade e estas precisam ser compreendidas para que a busca pela ecoeficiência se torne predominante. Chen et al. (2008) afirma que o governo em um país pode desempenhar um papel significativo em alcançar ecoeficiência, porém, não só o governo tem essa obrigação, mas toda a população, já que ambos impactam de forma negativa o meio ambiente ao usufruírem de produtos e serviços. É necessário que se busque o equilíbrio entre o consumo desenfreado e a limitação dos recursos naturais para que estes possam ser utilizados pelas futuras gerações.

\section{METODOLOGIA}

\section{Área Geográfica de Estudo e Fonte de Dados}


A pesquisa abrange 51 países distribuídos em cinco continentes (América, Ásia, África, Europa e Oceania), países estes selecionados pela disponibilidade de dados para o período estudado. Os dados utilizados foram de origem secundária obtidos no site do Banco Mundial, no período de 1991 a 2012.

\section{Envoltória com Livre Disposição (Free Disposal Hull - FDH)}

Utilizou-se a Envoltória com Livre Disposição (FDH - Free Disposal Hull) para calcular os escores de ecoeficiência, uma vez que esta técnica tem sido amplamente utilizada para este fim. O modelo FDH foi desenvolvido por Deprins et al. (1984) e apresenta as mesmas hipóteses do modelo BCC (DEA), com a diferença que ele utiliza como referência para os cálculos apenas das Unidades Tomadoras de Decisão (Decision Making Unit - DMU) reais, enquanto todos os outros modelos utilizam tanto DMUs reais quanto virtuais.

Supondo uma amostra $\chi(n)$, Deprins et al. (1984) propôs um estimador que não impõe restrição de convexidade sobre $\theta$, mas a suposição de livre disponibilidade. No método FDH, a eficiência orientada para os insumos é estimada ao comparar-se cada DMU, $\mathrm{i}=1, \ldots, \mathrm{N}$, com todos as outras DMUs, $\mathrm{j}=1, \ldots, \mathrm{N}$, que produzem, pelo menos, tanto quanto ela. O conjunto de pares de DMUs na amostra que satisfaz a condição $\mathrm{x}_{\mathrm{ij}}$ maior ou igual a $\mathrm{x}_{\mathrm{l}}$, para qualquer I é denotado por $\mathrm{B}_{\mathrm{i}}$. Entre os pares de DMUs aquele que exibe o consumo mínimo de insumos serve como referência para i e $\widehat{\theta_{l}^{F D H}}$ é calculado como o uso relativo dos insumos:

$$
\hat{\theta}_{i}^{F D H}=\min _{j \in B_{i}}\left\{\max _{k=1, \ldots, K}\left\{\frac{x_{k j}}{x_{k i}}\right\}\right\}
$$

As DMUs que apresentam um consumo mínimo de insumos entre todos os seus pares servem como sua própria referência. Neste caso $\theta_{i}^{F D H}$ assume o valor um. Todavia, até mesmo uma única DMU nos dados que apresente pequeno consumo de insumos pode tornar as demais ineficientes. O FDH é sensível a outliers e a erros de medição.

\section{Definição das variáveis para o cálculo de ecoeficiência}

A seleção das entradas (inputs) e saídas (outputs) do modelo foram baseadas no estudo de RobainaAlves et al. (2015). Os inputs utilizados: Emprego Total: mostra o número total de pessoas com idade entre 15 anos ou mais que estão trabalhando; Área de Floresta: área de terras naturais ou plantadas de árvores de pelo menos $5 \mathrm{~m}^{2}$, seja produtivo ou não, e exclui árvores em sistemas de produção agrícola e árvores em parques e jardins urbanos; Consumo de Energias Renováveis: é a quota de energia renovável do consumo final.

Os outputs utilizados: Produto Interno Bruto a preço de mercado (US\$ constante em 2010): é a soma do valor bruto acrescentado de todos os produtores residentes na economia, acrescido de eventuais impostos sobre os produtos e menos quaisquer subsídios não incluídos no valor dos produtos; Emissões Totais dos Gases do Efeito Estufa em kt de equivalente de $\mathrm{CO}_{2}$ : são constituídas por totais de $\mathrm{CO}_{2}$, excluindo a queima de biomassa de ciclo curto (como a queima de resíduos agrícolas e a queima de Savannah), incluindo outras 
queimaduras de biomassa (tais como incêndios florestais, turfeiras drenadas), todas as fontes antropogênicas de $\mathrm{CH} 4$, fontes de N2O e gases-F HFCs, PFCs e SF6. Para o cálculo da ecoeficiência o output utilizado foi a divisão entre o Produto Interno Bruto, considerada saída desejável, e as Emissões Totais dos Gases do Efeito Estufa, saída indesejável, sendo o cálculo foi realizado no programa estatístico STATA 12.0.

\section{Regressão Tobit}

O presente trabalho apresenta um modelo combinando a técnica de FDH e regressão Tobit para identificar quais as variáveis do modelo proposto influenciam o Índice de ecoeficiência dos países em estudo. A Regressão Tobit foi desenvolvida por James Tobin (1958). Segundo Amemiya (1984) a base do modelo Tobit é similar à regressão de mínimos quadrados, mas assume uma distribuição normal truncada ou censurada e torna-se um eficiente método para estimar a relação entre uma variável dependente truncada ou censurada e outras variáveis explanatórias. Para analisar o impacto de alguns fatores na determinação da ecoeficiência dos países, utilizou-se a análise de regressão Tobit. De posse dos escores de cada país estudado e de certas variáveis que possam explicar as diferenças na ecoeficiência entre eles, definiu-se o seguinte modelo de regressão: $\log (1 / \phi i)=\beta 0+\beta 1 \log X 1+\beta 2 \operatorname{LogX} 2+\beta 3 \log X 3+\ldots+\beta n \log X n+$ ui $(2) ;$ em que $\log (1 / \phi)$ é o logaritmo da inversa do escorre de ecoeficiência do i-ésimo país; $\beta$ indica os parâmetros a serem estimados, e é um indicador de elasticidade que fornece a participação relativa de cada variável na ecoeficiência de cada país; Os LogXs representam logaritmos das variáveis explicativas; o termo u é o erro estocástico, que se pressupõe ter média 0 e variância constante. Tendo em vista que a inversa do escorre de eficiência $(1 / \phi)$, tem valor limitado entre 0 e 1, torna-se necessário utilizar o modelo Tobit para estimar os parâmetros da regressão.

A variável dependente utilizada foi o Índice de Ecoeficiência (IE) e as variáveis explicativas foram o Rebanho Total/Área Rural (RT); Formação Bruta de Capital Fixo (FBCF), Consumo de Energias de Combustíveis Fósseis (\% do total de energia utilizada) (CCF); Taxa de Alfabetização de Adultos (TAA), população de 15 anos ou mais, ambos os sexos (\%); Qualidade do Governo (QG) (varia entre 0 e 1, consiste no valor médio das variáveis Corrupção, Lei e Ordem e Qualidade da Burocracia, valores mais altos indicam melhor qualidade do governo) e Rendas de Carvão (RC) (\% do PIB). Os dados foram obtidos no site do Banco Mundial, ano de 2012, para os 51 países que compõem a amostra. O programa estatístico utilizado para o cálculo da Regressão Tobit foi o STATA.

\section{RESULTADOS E DISCUSSÃO}

\section{Análise Descritiva}

Fez-se uma análise descritiva das variáveis explicativas utilizadas, como mostra a tabela 1. A média do Rebanho Total/Área Rural (RT) foi de 60,51. Os países com os maiores resultados nesta variável foram Bangladesh $(646,42)$, Países Baixos $(248,40)$ e Reino Unido $(229,85)$. Países como China $(54,19)$, Brasil $(28,72)$ 
e Estados Unidos (0,94), ocuparam, respectivamente, 16aㅡ, 25a e 47ạ posição. Os menores foram atribuídos ao Paraguai $(0,36)$ e Nepal $(0,42)$.

Bangladesh possui um dos maiores rebanhos de ovino e caprino do mundo. Já quando se trata de rebanho bovino o Brasil detém o segundo maior efetivo, segundo o Instituto Brasileiro de Geografia e Estatística (IBGE, 2016), sendo responsável por 22,5\% do rebanho mundial, atrás apenas da Índia (ocupa a sétima posição quando se utiliza Rebanho Total/Área Rural). Nesta pesquisa analisou-se o Rebanho Total, ovinos, caprinos e bovinos, divididos pela área rural total do país.

Tabela 1: Resumo das estatísticas descritivas das variáveis explicativas empregadas no modelo de Regressão Tobit.

\begin{tabular}{|l|l|l|l|l|}
\hline Variáveis & Média & Desvio-padrão & Mínimo & Máximo \\
\hline RT & 60,51 & 101,40 & 0,36 & 646,42 \\
\hline FBCF & $2,18 \mathrm{e}+11$ & $4,55 \mathrm{e}+11$ & $2,68 \mathrm{e}+09$ & $2,97 \mathrm{e}+12$ \\
\hline CCF & 64,94 & 25,36 & 3,22 & 96,29 \\
\hline TAA & 87,82 & 14,19 & 55,62 & 99,8 \\
\hline QG & 0,54 & 0,21 & 0,19 & 0,96 \\
\hline RC & 0,24 & 0,59 & 0,0000031 & 2,80 \\
\hline
\end{tabular}

A Formação Bruta de Capital Fixo (FBCF) alcançou a média de 2,18e+11 (US\$). Os maiores resultados ficaram com os Estados Unidos (2,96e+12), Japão (1,15e+12) e Alemanha $(7,08 e+11)$. O Brasil figurou entre os dez maiores, ocupando a sexta posição com um valor de 4,87e+11. A China (15a posição) obteve um resultado de 2,04e+11, sendo que os menores valores foram de Senegal e Nicarágua.

Segundo o Instituto de Pesquisa Econômica Aplicada (IPEA, 2004) a FBCF mede o quanto as empresas aumentaram os seus bens de capital, ou seja, aqueles bens que servem para produzir outros bens. São basicamente máquinas, equipamentos e material de construção. Ele é importante porque indica se a capacidade de produção do país está crescendo e também se os empresários estão confiantes no futuro. Por isso os países que alcançaram os melhores resultados são países ricos e desenvolvidos.

O Consumo de Combustíveis Fósseis (CCF) obteve a média de 64,94\% do consumo da energia total. As maiores porcentagens foram do Egito (96,29\%), Japão (94,53\%) e Austrália (94,29\%). China (87,90\%), Estados Unidos $(83,70 \%)$ e Brasil (56,54\%) ficaram entre as posições 13ạ e 35ạ. Os menores consumos foram de países do continente africano, África do Sul (3,22\%) e Moçambique (8,36\%). Corroborando com os resultados de que os países africanos utilizam bastante energias renováveis, devido, principalmente, a sua abundância em recursos naturais, apesar do baixo investimento no continente em tecnologias limpas.

Conforme a Bloomberg New Energy Finance até o ano de 2025 o mundo deve atingir o máximo de consumo de energia advinda dos combustíveis fósseis. Porém, a partir deste ano o consumo de energias renováveis deverá aumentar, mas não pelo declínio no consumo de combustíveis fósseis, e sim pelas mudanças características do mercado energético devido ao barateamento e ao avanço das tecnologias limpas.

Com relação a Taxa de Alfabetização de Adultos (TAA), população de 15 anos ou mais de ambos os sexos, a média obtida foi de $87,82 \%$. Os países que apresentaram os melhores resultados foram Noruega (99,8\%), Rússia $(99,71 \%)$ e Cuba $(99,71 \%)$. A China $(96,35 \%)$ ocupou a vigésima posição, Estados Unidos 
(95,3\%) a vigésima quarta e o Brasil $(92,58 \%)$ a trigésima quarta posição. As menores taxas de alfabetização foram no Senegal $(55,62 \%)$ e Paquistão $(56,44 \%)$.

Entre as dez melhores posições somente três países não pertenciam ao continente europeu, Cuba, Japão e Uruguai, em torno de $67 \%$ da amostra alcançou uma taxa de alfabetização acima dos $90 \%$, mas o continente que obteve os melhores resultados foi o europeu e os piores resultados foram alcançados pelos países da Ásia e da África. No continente americano os piores resultados foram de Honduras $(87,19 \%)$ e Nicarágua $(82,47 \%)$.

De acordo com a Unesco na América Latina e no Caribe, apenas Cuba atingiu os objetivos de Educação no período 2000-2015. Segundo o relatório, mais da metade dos países da América Latina conseguiram a universalização do ensino fundamental, mas ainda há 3,7 milhões de crianças sem escolarização. Estima em 33 milhões o número de adultos que carecem de conhecimentos básicos de leitura e escrita na América Latina, sendo 55\% mulheres. O relatório emite uma série de recomendações, entre elas a obrigação de se cursar um ano de ensino pré-escolar no mínimo, uma educação gratuita que deve abranger cadernos, livros, uniformes e transporte escolar, a aplicação dos convênios internacionais sobre idade mínima para o trabalho, a adequação das políticas de alfabetização às necessidades das comunidades e a redução das disparidades de gênero em todos os níveis.

A Qualidade do Governo (QG) obteve uma média de 0,54, os países com melhores resultados foram do continente europeu, Suécia $(0,96)$, Noruega $(0,94)$ e Países Baixos $(0,94)$, os Estados Unidos ocuparam a décima posição $(0,83)$, a China a vigésima $(0,47)$ e o Brasil a trigésima quarta posição $(0,42)$ e os piores resultados vieram da Venezuela $(0,19)$ e Sudão $(0,25)$. Conforme um estudo divulgado no ano de 2016 pelo Parlamento Europeu, a corrupção no continente gera prejuízo de quase 800 bilhões de libras por ano. Corrupção, que o relatório define como 'abuso de poder para benefício privado', pode variar de pagamento de propinas até autoridades abusando de seus poderes para obter contratos lucrativos e o custo da corrupção não é apenas financeiro. Também há significativos custos sociais e políticos, como maior desigualdade, altos níveis de crime organizado e leis mais fracas, alerta o estudo.

Venezuela continua sendo um dos países mais corruptos do mundo. De acordo com o Jornal El País (2014) as restrições ao exercício da liberdade de expressão e de participação cidadã - nos meios de comunicação e organismos não governamentais - somam-se a uma cultura de tolerância maior da corrupção, esses elementos limitam o controle social, num continente que ainda apresenta enormes assimetrias e disparidades. Nos países de qualificação pior, a corrupção é encarada com certa naturalidade e está 'impregnada' na sociedade de maneira sistêmica, os subornos são parte do dia a dia.

Por fim, as Rendas de Carvão (RC) em porcentagem do PIB atingiram uma média de 0,24 . As maiores rendas foram na África do Sul (2,80\%), Moçambique (1,94\%), China (1,56\%), Indonésia $(1,54 \%)$ e Índia (1,39\%). Os Estados Unidos figuraram entre os dez maiores, ocupando a nona posição, com um valor de 0,34\%. O Brasil ficou na posição vigésima segundo (0,00084\%). Os menores valores foram Suécia $(0,0000031)$ e Uruguai $(0,0000038)$. Estes países estão aumentando os investimentos em energias renováveis com o objetivo de num futuro próximo eliminar o uso de combustíveis fósseis.

O carvão possui um baixo custo e continua a ser o principal combustível do crescimento econômico 
na China e na Índia. De acordo com um estudo feito pelo Greenpeace (2016) e publicado pela Revista Exame a poluição do ar causada pelo uso contínuo de combustíveis fósseis, em especial o carvão, causou 1,6 milhão de mortes a mais do que o número projetado com base na taxa de crescimento do PIB nesses países para o ano 2015. Observam que à medida que os países se tornam mais ricos, eles geralmente desenvolvem indústrias menos poluentes. Mas no caso da Índia e da China, a tendência tem sido oposta. Apesar de seu crescimento econômico, esses dois países têm uma qualidade do ar particularmente sofrível. Contudo, a China adotou padrões de emissão para as usinas térmicas em 2011 e um plano de ação coordenado em 2013, o que de certa forma levou à redução dos níveis de poluição. Na Índia a situação é diferente. Mesmo diante de pressões ambientais crescentes, o país não dá sinais de diminuir o uso de energias sujas.

\section{Regressão Tobit}

A Regressão Tobit foi realizada com o objetivo de verificar as variáveis significantes para o Índice de Ecoeficiência dos países (pelo software STATA 12.0). Os resultados da regressão estão detalhados na tabela 2. Das seis variáveis utilizadas, cinco mostraram-se significativas ao nível de porcentagens diferenciadas. 0 Rebanho Total/Área Rural (RT) foi a única variável que não se mostrou significante, apesar de ser uma importante fonte emissora de gases do efeito estufa. $O$ sinal do coeficiente obtido foi o esperado, negativo, mostrando que o aumento do rebanho pode vir a diminuir o Índice de Ecoeficiência (IE).

Tabela 2: Resultados da Regressão Tobit.

\begin{tabular}{|l|l|l|l|l|}
\hline Variáveis & Coeficiente & Erro Padrão & $\mathbf{t}$ & $\mathbf{P}>|\boldsymbol{t}|$ \\
\hline Constante & $-0,1055174$ & 0,2424075 & $-0,44$ & 0,665 \\
\hline RT & $-0,0001337$ & 0,0003888 & $-0,34$ & 0,733 \\
\hline FBCF & $-2,06 \boldsymbol{e}^{-\mathbf{1 3}}$ & $8,56 \mathbf{e}^{-14}$ & $-2,41$ & $0,020^{* *}$ \\
\hline CCF & $-0,006398$ & 0,00176 & $-3,64$ & $0,001^{* *}$ \\
\hline TAA & 0,0083625 & 0,0035594 & 2,35 & $0,023^{* *}$ \\
\hline QG & 0,401178 & 0,2099754 & 1,91 & $0,062^{*}$ \\
\hline RC & $-0,1964907$ & $-3,20$ & $0,003^{* *}$ \\
\hline Num de obs & 51 & 0,0614907 & \\
\hline Log likelihood & -4.0489455 (modelo completo) & & \\
\hline LR chi2 (5) & 26.94 & & \\
\hline Prob $>$ chi2 & 0,0001 & & \\
\hline Pseudo-R2 & 0,7688 & & \\
\hline
\end{tabular}

O teste de Razão de Verossimilhança qui-quadrado (LR chi2) consiste que pelo menos um dos coeficientes de regressão não é igual a zero no modelo, verificando que o modelo apresentado é globalmente válido, indicando que os coeficientes estimados apresentam, conjuntamente, ajustamento satisfatório. A Prob>chi2 é a probabilidade de obter uma estatística de teste LR tão extremo quanto, ou até mais, do que a observada sob a hipótese nula (todos os coeficientes de regressão do modelo são iguais a zero). É a probabilidade de obter a estatística qui-quadrado $(26,94)$ se há de fato nenhum efeito das variáveis de previsão. 
O p-valor do teste afirma que pelo menos um dos coeficientes de regressão do modelo não é igual a zero. O Pseudo-R ${ }^{2}(0,729)$ corroboram com a indicação do bom ajustamento do modelo aos dados observados. Apesar de que para analisar o grau de ajuste em uma Regressão Tobit é mais indicado o teste de Razão de Verossimilhança qui-quadrado (LR chi2), já que a interpretação do pseudo-R2 não é a mesma do R2, porém, com cautela, pode-se analisar como uma aproximação da variação da variável dependente sobre a variável independente.

A interpretação dos coeficientes $\beta$ não são tão diretos quanto feitos em uma regressão linear, pois mudanças nas variáveis explicativas têm efeito não só sobre a média da variável se dentro do limite determinado, mas também sobre a probabilidade de estar dentro do limite. Apesar das limitações, os resultados indicam que as variáveis Formação Bruta de Capital Fixo (FBCF), Consumo de Combustíveis Fósseis (CCF) e Rendas de Carvão (RC) possuem um efeito negativo sobre o escore de eficiência, enquanto as variáveis Taxa de Alfabetização de Adultos (TAA) e Qualidade do Governo (QG) geram um efeito positivo.

Pode-se concluir que as variáveis FBCF, CCF e RC impactam negativamente no Índice de Ecoeficiência (IE) a uma significância de 5\%. Ou seja, quanto maior for a formação bruta de capital fixo, quanto mais as empresas aumentarem seus bens de capital, bens que servem para produzir outros bens, a tendência é que o IE diminua. Aumentando o consumo de combustíveis fósseis há uma diminuição do IE, o mesmo ocorre com as rendas advindas de carvão.

As constatações do modelo econométrico mostram que a Taxa de Alfabetização de Adultos (TAA - a um nível de 5\%) e a Qualidade do Governo (QG - a um nível de 10\%) impactam de forma positiva no IE e mostraram-se significantes. Um aumento na TAA, incorre num aumento do IE, já que se espera que quanto mais educada for a população, mais consciência ecológica estas terão, auxiliando assim na diminuição dos impactos causados ao meio ambiente pelo ser humano. A QG aumentando, também se espera que o IE aumente, pois, um governo menos corrupto, que segue as leis e a burocracia é na medida, não atrapalhando o dia a dia das empresas e dos consumidores, espera-se que tenham uma maior preocupação com a preservação dos recursos naturais para as futuras gerações.

\section{CONCLUSÕES}

Este estudo verificou através de uma Regressão Tobit as variáveis significantes para o Índice de Ecoeficiência de 51 países, entre os anos de 1991 a 2012. O Rebanho Total/Área Rural (RT) foi a única variável que não se mostrou significante. Os resultados indicam que as variáveis Formação Bruta de Capital Fixo (FBCF), Consumo de Combustíveis Fósseis (CCF) e Rendas de Carvão (RC) possuem um efeito negativo sobre o escore de eficiência, enquanto as variáveis Taxa de Alfabetização de Adultos (TAA) e Qualidade do Governo (QG) geram um efeito positivo.

A principal implicação dos resultados obtidos é de que são necessárias regulamentações mais rigorosas acerca do tema ambiental, principalmente para os países que apresentaram baixos valores de ecoeficiência. Uma sugestão para futuras pesquisas seria a inclusão de mais variáveis econômicas e ambientais, o aumento da amostra e do período utilizado, podendo obter resultados mais abrangentes e 
mais próximos da realidade. Ampliando assim o conhecimento sobre o assunto na busca por melhores alternativas para se alcançar a sustentabilidade tão necessária e urgente para as futuras gerações.

\section{REFERÊNCIAS}

AIDT, T. S.. Political Internalization of Economic Externalities and Environmental Policy. Journal of Public Economics, v.69, n.1, p.1-16, 1998.

AMEMIYA, T.. Tobit models a survey. Stanford University, Stanford, USA. Journal of Econometrics, v.24, n.1-2, p.3-61, 1984.

BANCO MUNDIAL. Dados ambientais, econômicos e sociais, 2016.

BLOOMBERG NEW ENERGY FINANCE. The World is close to the peak of consumption of fóssil fuels. 2016.

BRAUNGART, M.; MCDONOUGH, W.; BOLLINGER, A.. Cradleto-cradle design: creating healthy emissions e a strategy for eco-effective product and system design. Journal of Cleaner Production, v.15, n.13-14, p.1337-1348, 2006.

BRUSEKE, F. J.. Desestruturação e desenvolvimento. In: VIOLA, E.; FERREIRA, L. C.. Incertezas de sustentabilidade na globalização. Campinas: Unicamp, 1996. p. 103-132.

CALDERÓN, J. P.. La política ambiental en México: Gestión e instrumentos económicos, 2010, p.8.

CHEN, A. J. W.; BOUDREAU, M. C.; WATSON, R. T.. Information systems and ecological sustainability. Journal of Systems and Information Technology, v.10, n.3, p.186-201, 2008.

CHUNG, R. K.. Green Growth and Eco-efficiency: A Regional Strategy for Environmentally Sustainable Economic Growth in Asia and the Pacific. Presentation at the First Policy Consultation Forum of the Seoul Initiative on Green Growth. Seul, 2006.

DEPRINS, D.; SIMAR, L.; TULKENS, H.. Measuring Labor Inefficiency in Post Offices, in The Performance of Public Enterprises: Concepts and Measurements. Amsterdam, 1984.

EKLA. Programa Regional de Segurança Energética e Mudanças Climáticas da América Latina. História da Política Ambiental na Alemanha: perspectivas da CDU 1958- 2015. Lima: Konrad Adenauer Stiftung, 2016.

ERKKO, S.; MELANEN, M.; MICKWITZ, P.. Eco-efficiency in the finnish reports: a buzz word?. Journal of Cleaner Production, v.13, n.8, p.799-813, 2005.

GONÇALVES, J. C.. Homem Natureza: uma relação conflitante ao longo da história. Revista Multidisciplinar da UNIESP, n.6, p.171-177, 2007.

IBGE. Instituto Brasileiro de Geografia e Estatística. Rebanho bovino alcança a marca recorde de $\mathbf{2 1 5 , 2}$ milhões de cabeças. 2016.
IPEA. Instituto de Pesquisa Econômica Aplicada. O que é? Formação Bruta de Capital Fixo: Desafios do Desenvolvimento. 3 ed. 2004.

KAMIENIECKI, S.; KRAFT, M.. The Evolution of Research on U.S. Environmental Policy. Political Science, v.13, n.1, 2012.

LEHNI, M.. Eco-efficiency: creating more value with less impact. Switzerland: WBCSD, 2000.

LUSTOSA, M. C. J.. Regulamentação Ambiental, Inovação e Desenvolvimento na Austrália. Projeto 'Estudo Comparativo dos Sistemas de Inovação no Brasil, Rússia, Índia, China e África do Sul' - BRICS. Brasília, 2007.

LUSTOSA, M. C. J.; YOUNG, C. E. F.. Política Ambiental. In: KUPFER, D.; HASENCLEVER, L.. Economia industrial: fundamentos teóricos e práticos no Brasil. Rio de Janeiro: Campus, 2002, p.569-590.

MMA. Ministério do Meio Ambiente. Agenda 21, 2013. MINISTÉRIO DOS NEGÓCIOS ESTRANGEIROS DO JAPÃO. Japão: um país ecológico. Descobrindo o Japão. 7 ed. Tóquio, 2012.

NICUREBede, G. L.. O Progresso da Política Ambiental em Moçambique. Lisboa: Faculdade de Direito de Lisboa, 2013.

PIAGENTINI, P. M.; FAVARETO, A. S.. Instituições para regulação ambiental: o processo de licenciamento ambiental em quatro países produtores de hidroeletricidade. Revista Desenvolvimento e Meio Ambiente, v.30, p.31-43, 2014. DOI: http://dx.doi.org/10.5380/dma.v30i0.33029

ROBAINA-ALVES, M.; MOUTINHO, V.; MACEDO, P.. A new frontier approach to model the eco-efficiency in European countries. Journal of Cleaner Production, v.103, p.562-573, 2015.

SAY, J. B.. Tratado de economia política. São Paulo: Nova Cultura, 1986.

SILVA, A. M. D.; HERZ, M.. A Rússia e a Estrutura Institucional Internacional para o Desenvolvimento Sustentável. Núcleo de Política Internacional e Agenda Multilateral, 2012.

SIRVINSKAS, L. P.. Manual de Direito Ambiental. 7 ed. São Paulo: Saraiva, 2009.

THE ECONOMIST. Century Survey: Our Durable Planet. London: The Economist, 1999.

VIANA, M. B.. O meio ambiente no Mercosul. Biblioteca digital da Câmara dos Deputados. Centro de Documentação e Informação, 2004. 
YAMAGUCHI, T. E.; SOUZA, M. C. M.. França: A construção do direito ambiental em um país desenvolvido. Revista TÓPOS, v.5, n.2, p.47-66, 2011.
WBCSD. World Business Council For Sustainable Development. A ecoeficiência: criar mais valor com menos impacto. Lisboa: WBCSD, 2000.

A CBPC - Companhia Brasileira de Produção Científica (CNPJ: 11.221.422/0001-03) detém os direitos materiais desta publicação. Os direitos referem-se à publicação do trabalho em qualquer parte do mundo, incluindo os direitos às renovações, expansões e disseminações da contribuição, bem como outros direitos subsidiários. Todos os trabalhos publicados eletronicamente poderão posteriormente ser publicados em coletâneas impressas sob coordenação da Sustenere Publishing, da Companhia Brasileira de Produção Científica e seus parceiros autorizados. Os (as) autores (as) preservam os direitos autorais, mas não têm permissão para a publicação da contribuição em outro meio, impresso ou digital, em português ou em tradução. 